\title{
Circular Economy and the Transition to a Sustainable Society: Integrated Assessment Methods for a New Paradigm
}

\author{
Mariana Oliveira $^{1}$ - Mécia Miguel ${ }^{2,6} \cdot$ Sven Kevin van Langen ${ }^{1,5} \cdot$ Amos Ncube $^{1}$ • \\ Amalia Zucaro $^{3}$ - Gabriella Fiorentino ${ }^{3}$ - Renato Passaro ${ }^{4} \cdot$ Remo Santagata $^{1}$. \\ Nick Coleman ${ }^{6}$ - Benjamin H. Lowe ${ }^{2} \cdot$ Sergio Ulgiati ${ }^{7,8} \cdot$ Andrea Genovese $^{2}$
}

Received: 12 February 2021 / Accepted: 24 February 2021 / Published online: 22 March 2021

(C) The Author(s) 2021

\begin{abstract}
The circular economy concept has recently gained prominence in political debate and corporate discourse around the world as a pathway towards sustainability. The academic debate is characterised by several and sometimes very contrasting definitions of the concept. We claim here that the issue is not finding silver-bullet solutions that will simultaneously support population growth, increasing affluence and environmental resource regeneration. We argue that a clearer definition is needed for the circular economy concept, in terms of strategies, objectives, future states and stakeholders' needs. Also, assessment methods need to be developed for keeping track of the transition towards a circular economy. Within this context, this paper establishes the need for a multistakeholder, multi-dimensional and multi-criteria approach for the evaluation of the transition towards a circular economy across different time and spatial scales, as well as multiple sustainability dimensions.
\end{abstract}

Keywords Circular economy · Environmental accounting methods $\cdot$ LCA $\cdot$ Sustainability · Economic transition · Wellbeing

\section{Introduction}

The emerging circular economy (CE) paradigm is expected to transform the relationships between ecological and economic systems. This paradigm argues for an economic system in which reductions in resource use and the mitigation of environmental impacts play a dominant role [1-6]. To plan for a reduction in resource use, a radically different organisation of production and consumption patterns is required. It is not just a matter of recycling plastic

\section{Sergio Ulgiati}

sergio.ulgiati@uniparthenope.it

Extended author information available on the last page of the article 
bottles before they create plastic islands in the oceans, but instead questioning the need and value of bottled water and soft drinks on our tables; it is not a matter of promoting reuse and recycle loops for fast-fashion items, but rather questioning the way we design and use products from the textile industry; it is not just a matter of improving the recycling of e-waste and avoiding its illegal export to Global South countries, but rather questioning production patterns driven by planned obsolescence and devising responsible innovation dynamics.

Planning for different production and consumption patterns ultimately requires a deep rethinking of economic development and societal wellbeing. Planning for more durable goods calls for an end to current mechanisms, which are aimed at achieving artificial economic growth objectives [7]. Planning for shared and collaborative community services calls for an alternative to the worldwide competition for scarce resources.

Within a CE, resources and by-products will have to undergo multiple production and consumption cycles and end-of-life treatments under the reduce, reuse and recycle (3R) imperative to convert linear production systems into closed-loop systems [4, 8]. These systems should ideally be powered by renewable energy given the growing awareness of limited resource availability worldwide. However, limiting our focus to end-of-life solutions is not a sufficient strategy. Recycling requires energy, and most materials cannot be subject to unlimited recycling without some losses of quantity and quality. Also, in a recent briefing paper, the European Parliament admitted that effective mitigation actions for the current environmental crisis need to be based on sufficiency-oriented strategies and strict enforcement of absolute reduction targets [9].

A new economy, based on societal well-being, would need to rely upon local value chains, social and ecosystem resilience, and at the same time, the reduction of social and economic vulnerabilities [10]. For these reasons, companies should radically change their business and operating models under a CE paradigm. In addition, society as a whole and individuals will have to change their lifestyles and attitudes towards affluence, growth, community services and production and consumption to meet the challenges posed by population growth, environmental degradation, climate change and unexpected events (e.g., wars, diseases, pandemics and migrations) [11].

However, scholars have criticised several underlying assumptions of CE. Giampietro and Funtowicz [12] and Murray et al. [13] have questioned the biophysical feasibility of CE. Also, the apolitical framing of the $\mathrm{CE}$ agenda, its potentially contested nature and its underlying ambiguity on some crucial issues (such as the attitude towards economic growth) have been highlighted by several authors $[14,15]$. The mainstream narrative assumes that $\mathrm{CE}$ practises are, by definition, sustainable [16] and fails to consider impacts on social equity and intergenerational wellbeing [5].

$\mathrm{CE}$ is championed as a source of social benefits, mainly through job creation, longer product lifetime in the use phase and increased welfare for lower-income households [1]. Policy-makers and businesses currently try to implement circular strategies at different scales, while academics engage in conceptual discussions, both without clear guidance or coherent metrics to assess the impacts and benefits of proposed CE initiatives [17, 18], which mainly translate into material recovery strategies with a strong focus on recycling [19].

\section{The Emergence of Diverging Paradigms}

The promotion of closed-loop supply chains and recycling pathways does not automatically lead us to more sustainable societies. Just as an example, since the adoption of the EU CE 
Action Plan [20], the improvements in recycling rates have been overshadowed by the increasing consumption of raw materials - a $4.5 \%$ increase in domestic material consumption between 2016-18 [21]. Additionally, when examining macro-economic data, similar concerns arise, leading us to raise some crucial questions. Certainly, the first question is whether worldwide economies are on track to minimise resource and energy use through CE practises, or perhaps they are only increasing resource productivity by building on the existing (and still growing) linear economy and implementing the rebound effect theorised by Jevons in 1905 $[22,23]$. Considering the reliance on global supply chains, it is still unclear how CE can make production more local. Furthermore, concerning the creation of CE-related new jobs, will they benefit societal wellbeing, or will they add more harm (e.g., unhealthy working conditions and low wages in recycling plants)? Also, is the transition towards a CE to happen through planning and coordination, or should it be driven by market forces? Currently, we cannot provide an answer to these questions due to a lack of consensus on the transition, as well as suitable measurement and monitoring frameworks.

It should be stressed that measuring and monitoring should not just encompass the usual list of linear economy parameters (e.g., GDP, market price of resources and financial trade balances), but instead indicators capable of accounting for the society that we want to build for the generations to come, such as quality of life, community links, wellbeing, environmental integrity, social diversity and stability and equal distribution of resources. The emergence of a new paradigm, which is ultimately based on new values calls for the design and development of new indicators and new metrics. To quote Odum and Odum [24]: "Valuation is one mechanism by which humans organise occupancy and use of large-scale ecosystems and regions, such as watersheds, estuaries, cities, states, nations, and ultimately the whole earth (the global perspective) [...]. Ecosystems of the world are threatened because market prices are used to evaluate them".

Economic growth requires the continuous supply of materials, non-renewable resources and fossil fuels coupled with monetary flows [25]. The limited availability of resources and the struggle for boundless economic growth generates socio-environmental chaos and events that are extremely harmful to society and ecosystems (e.g., hurricanes, droughts, increased global hunger, floods, heatwaves, forest fires and pandemics), thus, signalling the urgency for a change of direction [26, 27]. Moreover, a reductionist version of a $\mathrm{CE}$, based on simple corrective actions to business-as-usual practices, might reinforce the existing linear economic systems, increase wealth disparity, and support human injustice by increasing the market price of all materials. As a result, this could concentrate more economic power in the economies that are already developed and capable of implementing CE practices, and coupled with a rebound effect, CE could therefore become a tool for economic growth and increased materials consumption. Alternatively, an ambitious CE may replace the old economic systems with a more balanced, environmentally friendly and fair business model that emphasises collaboration instead of competition, reliance on renewable resources and materials, community services, environmental integrity, redistributive justice, and closed loops instead of continuous waste generation (see Table 1, adapted from [28]).

In other words, depending on the selection of overarching values, $\mathrm{CE}$ can be either a tool for sustainable development or a tool for increased 'sustainable' planetary degradation and social instability that merely focusses on more efficient resource utilisation, rather than on its reduction. The challenge here is to assess the distinctive societal values of the development model we desire (for now and generations to come), which should reflect fundamental choices 
Table 1 Features of linear and circular economy (adapted from [28])

\begin{tabular}{ll}
\hline Linear economy & Circular economy \\
\hline Business based & Network-based \\
Stand-alone activities & Collaborative, nexus oriented \\
Mono-criteria (value based on maximum income) & Multi-criteria (value based on selected characteristics) \\
Design and planning for unlimited growth & Resources are limited \\
Conservative (more-of-the-same approach) & Regenerative (saving resource generation patterns), \\
& flexible about pursued results \\
Concentration (getting more, spending less) & Redistributive (fair resource allocation) \\
\hline
\end{tabular}

that integrate the three sustainability dimensions (economic, environmental and social). Measuring and monitoring are crucial in any transition but might lose importance and effectiveness if these activities are not linked to the identification of the values we pursue and want to implement in society: a model of society based on participatory, democratic and communityoriented choices (renewable resources, environmental protection, waste minimisation and circular patterns, maximisation of citizens' wellbeing, responsible consumption models, and social equity, amongst others). Only once values are clear and goals agreed upon, the second crucial step is to design an integrated framework of multi-dimensional and multi-criteria evaluation methods and indicators capable of measuring, evaluating, monitoring and managing the complexity of a sustainable transition to CE. Within a clear and shared framework of values, a multi-dimensional measuring tool plays a key role in managing and monitoring a transition that, by its nature, is dynamic, flexible and progressive, driven by both quality and quantity, and finally, relies on accurate feedback mechanisms to improve the measurement itself.

As mentioned above, it is not the goal of the present paper to identify the best method, if any. Our aim is instead to design a procedure that links and/or integrates proven methods in order to get the best out of each of them. This might assist with monitoring progress towards the $\mathrm{CE}$ and drive the transition from a Business-as-Usual (linear) to a regenerative and wellbeing-oriented (circular) economy.

\section{Measuring, Monitoring, and Understanding}

A common quote by Lord Kelvin, one of the fathers of thermodynamics, claimed the absolute importance of measuring for understanding: "When you can measure what you are speaking about, and express it in numbers, you know something about it." [29]. While advocating the importance of measuring, Kelvin also underlined that measuring tools can allow us to know something about a phenomenon but not everything. It is impossible to address the complexity of all the sustainability issues that society should monitor and manage in quantitative terms only, and this is particularly true if using a mono-dimensional measure that might be affected by a reductionist perspective [30]. Gasparatos and Scolobig [31] clarified that whilst environmental and social sustainability can only be partially quantified, the importance of these dimensions should not be disregarded. Indeed, supporting policymakers and involving stakeholders is undoubtedly made easier by an accurate set of quantitative indicators at appropriate spatiotemporal scales. 
As shown in Fig. 1, the transition towards a CE starts from the existing interaction between populations, industrial systems and their environments (depicted at the centre of the diagram). From the inside to the outside of Fig. 1, we see that the population and the surrounding environment, the environment and the production sectors and finally the production sectors, and population again, are all linked by a mutual interaction based on an exchange of support and resources, demand and supply, and care and wellbeing. Environmental, economic and social dimensions are all simultaneously involved. A large number of issues need to be addressed, and numerous stakeholders need to be engaged, to the extent that it is not sufficient to just say that a given amount of energy was saved or that in a given year the GDP has grown. All dimensions are important for the sustainable coexistence of all species, including humans. Decision making (point 4 of the outer circle in Fig. 1) needs integrated evaluations (point 3 of the outer circle), which in turn require planning (point 2 of the outer circle). All of these translate into the wellknown 3Rs (reduce, reuse and recycle) of a CE, where reduce stands for planning revised production and consumption patterns according to self-sufficiency objectives, reuse and recycle suggest extending the lifecycle of products and resources, respectively, and all of them suggest renewability (water cycle, solar and wind energy, photosynthesis, renewable alternatives to fossil fuels and minerals). The multi-stakeholder and multidimensional nature of the transition, highlighted in Fig. 1, requires a multifaceted approach for the evaluation of a complex problem.

Numerous methods can be used to measure and monitor resource use and associated impacts, as well as costs and benefits. The goal of this paper is not to select the best method, but instead to identify how to integrate several methods to achieve the best understanding of the cases or processes under study. In different situations, other methods may be selected, but the integration procedure (select space and time scales, select representative data, design a roadmap for sequential or parallel method application, and compare results) would still hold.

A standardised CE evaluation method should support strategic decisions and monitor the progress towards sustainable development. In this view, it is also relevant to consider the way environmental goods are treated from an economic point of view. The total cost of ownership to (global) society is not represented by the price consumers pay, which is the ultimate measure of value in mainstream economic indicators. In general, environmental goods have a public nature and, according to economic logic, do not have a price since they are not exchangeable on the market. However, not having a price does not mean they are worthless: the economic appreciation of ecosystems stems from the perceived utility that they provide to stakeholders. The concept of ecosystem services which reflects this economic (or utilitarian) logic has deep roots; it has gained increasing importance and is currently involved in economic decisionmaking and strategic planning mechanisms [32]. Hence, the attribution of an economic value to ecosystems is increasingly proposed as the first step in their maintenance.

However, according to Kallis et al. [33], placing monetary values on resources or ecosystem functions might not solve crucial challenges related to the transition to sustainable futures, because (i) it might not improve the environmental conditions at stake; (ii) it might not reduce inequalities related to access to resources; (iii) it is likely to suppress alternative valuation approaches; (iv) it might foster processes of appropriation of the commons [33]. Furthermore, monetary valuation approaches must be handled with care, as they might provide the methodological and discursive legitimation for commodification of nature that might worsen socioenvironmental conditions [33]. 


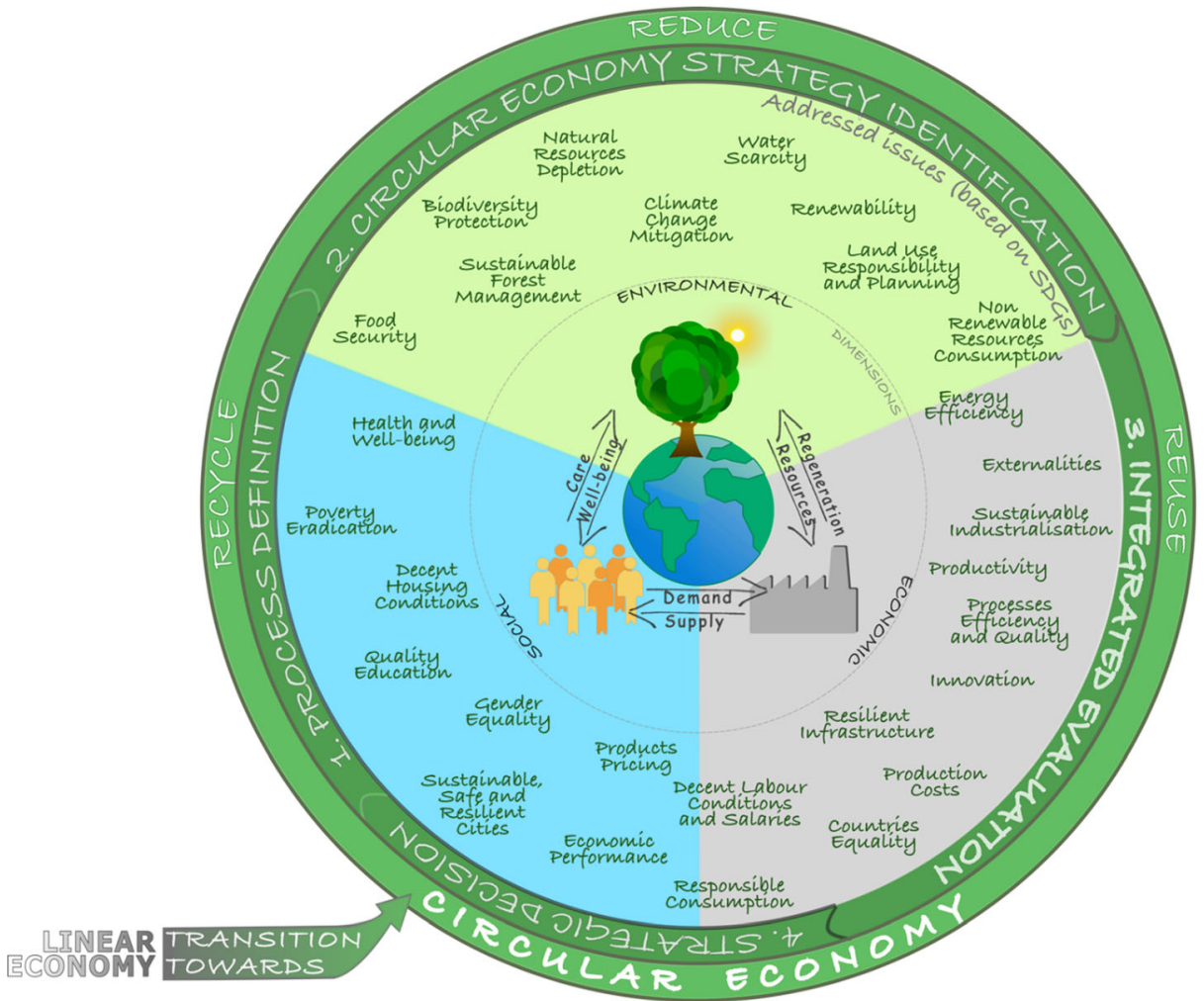

Fig. 1 Sustainable CE evaluation methodology framework

As such, as also highlighted by Gasparatos and Scolobig [31], the challenge is to design nonreductionist multi-dimensional and multi-criteria approaches that can evaluate the transition to a $\mathrm{CE}$ by coherently analysing insights derived from the simultaneous application of different yet complementary methods. To this end, our proposed framework contends that the integration and use of the selected methods - which have been designed to capture different sustainability dimensions - could provide a more comprehensive understanding of CE and support decision-makers. Indeed, these methods complement each other in the sense that the output from one method can act as the input for another method (see Figs. 2 and 3). A short description of the methods selected for use in this framework-Life Cycle Assessment, Social Life Cycle Assessment, Life Cycle Costing, Emergy Accounting and Sustainable value Chain Mapping - is provided below.

\section{Life Cycle Assessment}

Within a Life Cycle Assessment (LCA) perspective, products and processes are investigated from cradle to grave by listing their resource use and related emissions, after selecting the goal, scope, boundary, and functional unit (FU). Several software packages and databases — such as Ecoinvent, Gabi and Sima Pro - are available so that data from previous studies can be incorporated into the assessment. The results are formulated in terms of multidisciplinary indicators that confer impacts (for example, Global Warming Potential, Fossil Energy Depletion, Human Toxicity Potential, Ecosystem Toxicity Potential, Water Use, Land Use, Freshwater Eutrophication Potential, amongst 


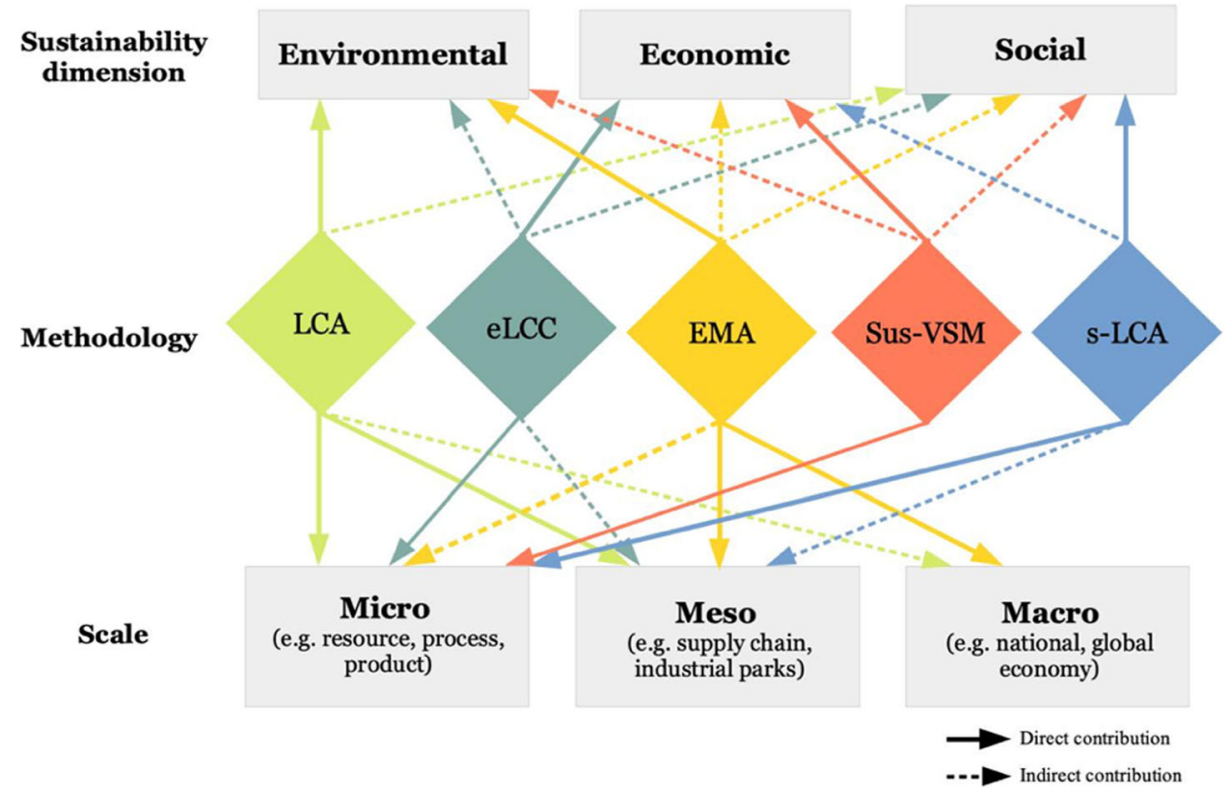

Fig. 2 Overview of the assessment methods, scales of implementation and their contribution to understanding and pursuing sustainability challenges and policies

others) related to the selected FU, boundary and time scale. The results are also tested for uncertainty and sensitivity, according to ISO 14040/2006 and 14044/2006 standards and ILCD Handbook guidelines [34]. The interpretation of results and suggested improvements may lead to decreased burdens in some impact categories and increased impacts in others, which means there is a need to generate and discuss potential scenarios. The benefit of LCA is a detailed knowledge about upstream and downstream environmental impacts generated by a product or service over its life cycle. LCA can also be integrated with Environmentally Extended Input-Output Analysis [35] to account for upstream inputs and their environmental impacts, addressing system boundaries and truncation errors [36].

\section{Social LCA}

Social LCA (S-LCA) follows a similar cradle-to-grave approach as environmental LCA, but its focus is on social aspects related to the quality of life and wellbeing of all categories of stakeholders involved in the processes under review. S-LCA inventories range from child labour to freedom of association, from cultural heritage to access to intangible resources, from gender discrimination to health and safety and from indigenous rights to corruption [37]. Benefits from Social LCA are detailed knowledge about social and wellbeing impacts generated by a process, in a framework that is very close to the sustainable Development Goals of United Nations and to the ISO 26000 standard regarding Corporate Social Responsibility [38].

\section{Life Cycle Costing}

Life Cycle Costing (LCC) assesses the costs faced before, during and after the manufacturing of a product. For example, even when we think we are paying for a 


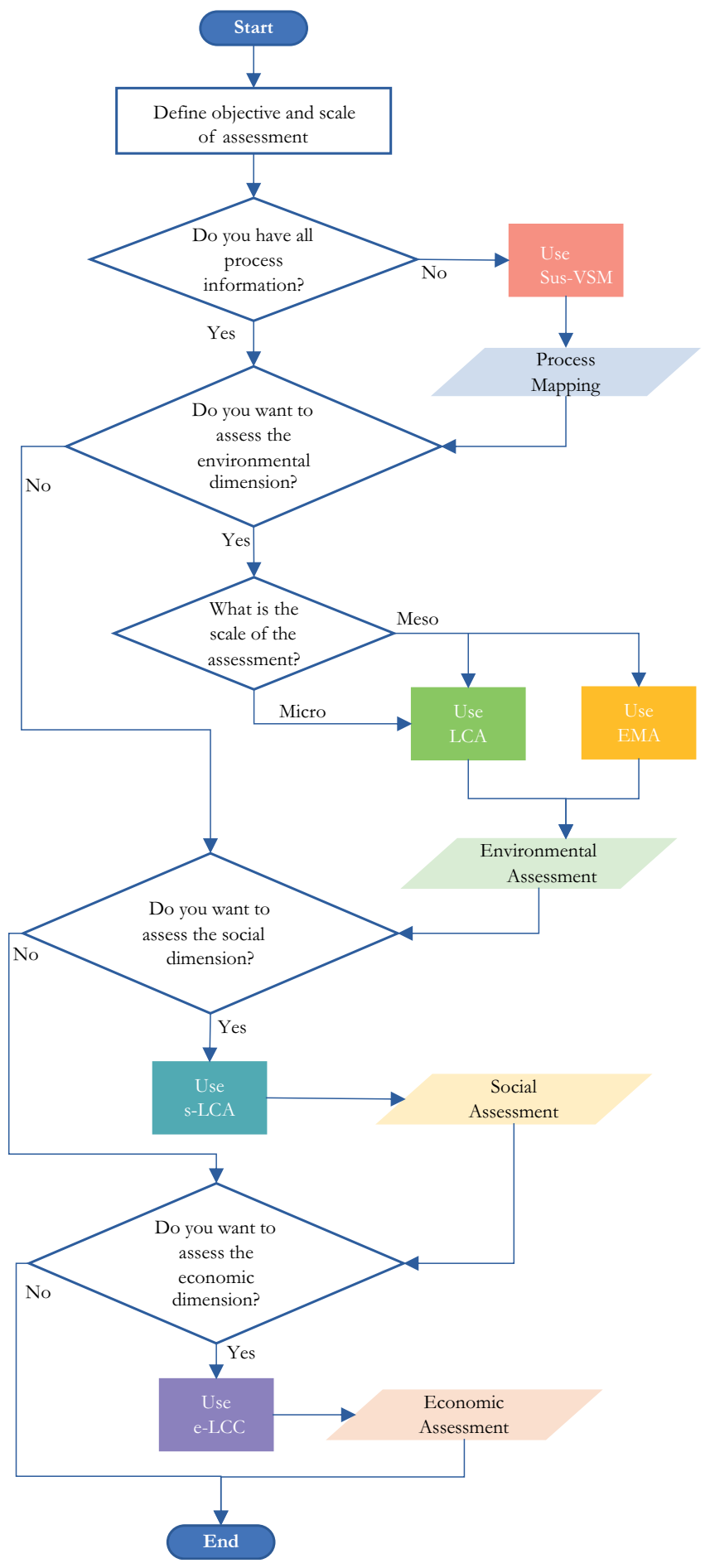

Fig. 3 A potential procedure for the selection and integration of assessment methods 
gold ring, we are actually paying for the inputs required in order to acquire the gold mine, extract the mineral, refine it, design and manufacture the ring, advertise and sell the ring, and dispose of the waste generated over the entire production chain, even if we do not pay nature for generating the mineral resource [39]. LCC can be run in parallel to LCA with the aim of understanding in which step of the production process costs increase and why, and how these costs can be decreased through better process design. Recent attempts (see, for instance: $[40,41]$ ) have tried to integrate LCC and LCA, taking advantage of the common cradle-to-grave approach to combine economic and environmental evaluations.

\section{Emergy Accounting}

Generally, energy accounting methods focus on what can be extracted from a resource (e.g., exergy accounting), i.e., they apply a user-side framework. Emergy Accounting (EMA) uses the opposite approach, a supply-side or donor-side point of view. Emergy is defined as the total amount, $U$, of available energy of one kind (usually, solar energy) needed directly or indirectly to make a product or a service $[42,43]$. Its unit is the solar emjoule (sej). The emergy needed for one unit of a product or service is named Unit Emergy Value (UEV) and measured as sej/J or sej/g. The emergy value expresses how much environmental work is provided by the biosphere to generate (and regenerate) a resource or a good. The emergy method provides several indicators in addition to total $U$ (size of the system) and UEV (generation efficiency), including the Emergy Yield Ratio (EYR, reliance on local resources), the Environmental Loading Ratio (ELR, distance from environmental equilibrium), the Emergy-to-money Ratio (EMR, efficiency in generating economic value), the Emergy Exchange Ratio (EER, the advantage in trade), amongst others. It is important to clarify that emergy is not energy, nor a typo. Given that emergy accounts for the entire chain of processes that lead from driving sources of planetary dynamics (solar, deep heat, gravitational potential) to the considered resource, the " $\mathrm{m}$ " in its spelling refers to the "memory" of processes over the entire supply chain. The benefit of emergy accounting comes from the fact that it provides a measure of environmental support or environmental cost in a comparable unit over the entire generation process.

While LCA applies a consumer side perspective, through its donor side perspective, EMA expands the boundaries of the system over the entire biosphere space and time scales. As such, the two methods can be combined to offer complementary perspectives. For instance, Corcelli et al. [44] investigate one of the biggest papermaking companies worldwide employing LCA to assess the environmental impacts of papermaking and evaluate circular strategies; Corcelli et al. [45] expand the scale of the assessment of the same process using EMA to evaluate the biosphere contribution to the process itself, also incorporating the need for regeneration of resources. Also, based on these early studies, Santagata et al. [46] provided a procedure based on the sequential and integrated application of LCA and EMA methods called LEAF (LCA \& EMA Applied Framework). Such integrated procedures enable the evaluation of CE scenarios based on different practices, technological options and energy solutions, thus providing support to policymaking. 


\section{Sustainable Value Stream Mapping}

Sustainable Value Stream Mapping (Sus-VSM) analyses individual processes at the micro-scale, accounting for process inputs generating outputs [47]. The Sus-VSM method aims to decrease waste from any step of the production processes [48], and in doing so, prevent energy, water and material waste, all of which are relevant to CE. Indeed, designing processes for decreased waste generation contributes to the planning phase of $\mathrm{CE}$, limiting the need for subsequent reuse or recycling. Sus-VSM extends the economic orientation of the original VSM method by also tracking several environmental and social indicators, thus making it more appropriate for assessing the sustainability of a process.

An integration of Sus-VSM with Life Cycle Assessment has been proposed by Vinodh et al. [49] and Salvador et al. [50], which aims to provide a simple tool for prioritising measures to improve environmental-economic performance according to a continuous improvement approach. A recent call to extend Sus-VSM further to make it more suitable for the evaluation of CE patterns was launched by Hedlund et al. [51] who expanded Sus-VSM to better evaluate products in use and under maintenance, as well as re-use, remanufacturing, recycling, and incineration processes. Benefits from Sus-VSM include decreased demand for resources and increased conversion efficiency into products and services, thus resulting in reductions in waste generation, pollution and costs.

\section{Benefits from Integration}

Each one of the above methods has been designed to respond to a specific set of questions. These can include the cost of labour, the environmental burden with the generation of resources, and the environmental impact. Each of the methods presented has developed a set of indicators, which can be compared to each other, recalculated at larger scales and used together synergistically. Sometimes, they might show contradictory behaviours and might need to be interpreted holistically; this might provide a deeper understanding of the phenomena under investigation.

Integrating these methods could translate into a useful and synergistic accounting exercise, showing how these methods overlap each other and support each other's results (Fig. 2). For example, Sus-VSM assesses production and material recovery processes (e.g., remanufacturing), identifying inputs and outputs, improving knowledge about each process [47], and generating input data for performing LCA, LCC, S-LCA and EMA. LCA analyses the physical flows under human control, capturing the resource use and environmental consequences of a given product or process according to standard procedures (ISO 14040/2006; ISO 14040/2006) [34]. Furthermore, LCA applies a consumer side perspective. Its space and time scales are confined within a system boundary capable of including all the process phases in terms of location and durability and their direct impacts on the areas investigated [46]. This can be further expanded through the integration of LCA and EMA, as EMA expands the boundaries of the system over the entire biosphere space and time scales. As such, the two methods can be combined to offer complementary perspectives. 
On the other hand, LCC adds economic transactions and calculates costs and revenues during the life cycle of products or services. By including externalities and costs met by actors outside of the company boundaries, the step-by-step environmental cost of a product or service is better identified with LCC; this can inform consumers' decisions and support the dissemination of products with better environmental performance [52]. The social dimension can be assessed with s-LCA, looking at the impact on affected workers and communities during a product's life cycle [53-57]. Sus-VSM is very process-oriented but provides a way to link the evaluation of different processes encountered in a product/service life-cycle, potentially providing useful mapping which can serve as a prerequisite for undertaking LCA exercises.

LCA, LCC and s-LCA are life cycle thinking methods that assess all the stages associated with products or services, thus accounting for different stakeholders' perspectives and preventing burden shifting between them.

\section{From Linear to Circular Evaluation Models}

Integrated evaluation should be the core of any accounting approach, especially when dealing with the transition towards a CE. As mentioned, the methods applied to monitor the transition should account for resource consumption and regeneration by nature, more effective materials use, market costs and investments, environmental and societal services, cradle to grave process parameters, and direct and indirect labour, all at different spatiotemporal scales.

Furthermore, the abovementioned description of the stand-alone methods has highlighted the potential to integrate alternative approaches with LCA. The intrinsically non-reductionist cradle-to-grave view of LCA, which can be extended to the whole economy through Environmentally Extended Input-Output Analysis, and to the whole biosphere through EMA, can be considered the fulcrum of an integrated multi-dimensional and multi-criteria approach to the evaluation of the transition towards a CE. This was also suggested by Ulgiati et al. [58, 59], who advocated, depending on the complexity of the investigated system, for the integration of upstream and downstream points of view, local and global scales, embodying time in resources, and appropriate standardisation and weighting methods. Such an approach builds on the synergies between LCA and all the other proposed methods, allowing the evaluation of the transition towards a $\mathrm{CE}$ at different scales and across different sustainability dimensions.

As shown in Fig. 2, an integrated assessment framework starts from the identification of the process and the scale it occurs: micro (a specific process, a company), meso (a sector, a supply chain, an industrial park) or macro (a city, a region, a nation) [4, 60]. At this point, boundaries are more easily defined, and data can be collected in an organised and systematic way.

The complexity of the CE concept brings together multiple disciplines into one common framework, with social, economic, and environmental dimensions to be addressed. Of course, the different disciplines will carry their own established methods and tools for assessment, coupled with challenges in data collection and interpretation. The interactions between the different methods also apply across different scales of interest (micro, meso, and macro), as shown in Fig. 2. On any scale, assessment tools should enable users to capture the multidimensional aspects of $\mathrm{CE}$ as well as to minimise fragmentation by clearly connecting circularity and planetary boundaries. Using the above methods in sequence or association may help understand the consequences of policy or business choices [46]. However, all of these methods were originally designed for linear production systems and may have limitations when assessing circularity and feedback loops, in particular for issues associated with reuse, 
refurbishing, and repurposing [61]. Figure 2 highlights the need for, and the possibility of, integration across scales.

Finally, the flowchart illustrated in Fig. 3 can be employed to aid in the selection of which method is more suitable for practitioners to apply according to their objectives and scale of assessment. To better understand how the framework can be used practically, the example of the automotive industry can be considered. In this industry, repair, remanufacturing, and recycling levels are relatively high compared to most industrial sectors, and a lot of research has been done on production process optimisation and separately on remanufacturing processes. Nonetheless, if a product's design is conceptualised for optimising the production process, it might be harder to remanufacture. While if the design is heavily focused on remanufacturing, it might be harder to produce initially. In such a situation, EMA could be used to account for the non-renewable and renewable resources required and to ascertain if a given economy can afford such resource expenditure (precautionary principle) or if a production pattern should simply be abandoned and replaced. This information could be used as an input to LCA and LCC assessments, which can be run in parallel to evaluate the environmental and economic implications of different production alternatives. Finally, the LCA and LCC outcomes can be integrated into VSM to better compare manufacturing and remanufacturing options and to decide further optimisation techniques for each.

\section{Conclusions}

This paper has established the need for a multi-stakeholder, multi-dimensional and multicriteria approach to evaluate the transition towards a CE. While individual assessment methods might be capable of addressing the issues they were designed for, the transition towards a $\mathrm{CE}$ requires evaluation tools capable of synergistically evaluating performance across different time and spatial scales as well as multiple sustainability dimensions. This is a crucial need for the large number of researchers, businesses, policymakers and stakeholders currently involved in the development and implementation of CE-inspired solutions in different sectors and at different scales. A lack of such tools might result in additional difficulties in agreeing upon transition pathways and reaching a consensus on the remedial measures to be adopted. To prevent such a risk, an early conceptualisation of how several evaluation tools could be integrated has been provided, with the aim of embracing the social, environmental, and economic dimensions for assessing the transition to a CE.

Acknowledgements The authors gratefully acknowledge the funding support from the projects "Realising the Transition towards the Circular Economy: Models, Methods and Applications (ReTraCE)", funded by the European Commission H2020-MSCA-ITN- 2018 programme (Grant Agreement Number: 814247) and "Promoting Circular Economy in the Food Supply Chain (ProCEedS)", funded by European Commission H2020MSCA-RISE-2018 programme (Grant Agreement Number: 823967).

Funding Open access funding provided by Università Parthenope di Napoli within the CRUI-CARE Agreement.

\section{Declarations}

Conflict of interest The authors declare no conflict of interest. 
Open Access This article is licensed under a Creative Commons Attribution 4.0 International License, which permits use, sharing, adaptation, distribution and reproduction in any medium or format, as long as you give appropriate credit to the original author(s) and the source, provide a link to the Creative Commons licence, and indicate if changes were made. The images or other third party material in this article are included in the article's Creative Commons licence, unless indicated otherwise in a credit line to the material. If material is not included in the article's Creative Commons licence and your intended use is not permitted by statutory regulation or exceeds the permitted use, you will need to obtain permission directly from the copyright holder. To view a copy of this licence, visit http://creativecommons.org/licenses/by/4.0/.

\section{References}

1. Ellen MacArthur Foundation (2012) Towards the Circular Economy Vol. 1: an economic and business rationale for an accelerated transition 1 .

2. European Commission, 2012. Innovating for sustainable growth: a bioeconomy for Europe, Publications Office of the European Union. Luxembourg. https://doi.org/10.2777/6462

3. European Commission, 2015. Closing the loop - an EU action plan for the circular economy.

4. Ghisellini P, Cialani C, Ulgiati S (2016) A review on circular economy: the expected transition to a balanced interplay of environmental and economic systems. J Clean Prod 114:11-32. https://doi.org/10.1016/j. jclepro.2015.09.007

5. Geissdoerfer M, Savaget P, Bocken NMP, Hultink EJ (2017) The circular economy - a new sustainability paradigm? J Clean Prod 143:757-768. https://doi.org/10.1016/j.jclepro.2016.12.048

6. Merli R, Preziosi M, Acampora A (2018) How do scholars approach the circular economy? A systematic literature review. J Clean Prod 178:703-722. https://doi.org/10.1016/j.jclepro.2017.12.112

7. Odum HT, Odum EC (2001) A prosperous way down: principles and policies, 1st edn. University Press of Colorado, Boulder, Colorado

8. Genovese A, Acquaye AA, Figueroa A, Koh SCL (2017) Sustainable supply chain management and the transition towards a circular economy: evidence and some applications. Omega (United Kingdom) 66:344 357. https://doi.org/10.1016/j.omega.2015.05.015

9. European Parliament, 2021. Opportunities of post COVID-19 European recovery funds in transitioning towards a circular and climate neutral economy. Briefing paper available at: https://www.europarl.europa. eu/RegData/etudes/BRIE/2020/658186/IPOL_BRI(2020)658186_EN.pdf

10. Carr ER (2020) Resilient livelihoods in an era of global transformation. Glob Environ Chang 64:102155

11. Wiedmann T, Lenzen M, Keyßer LT, Steinberger JK (2020) Scientists' warning on affluence. Nat Commun 11:3107. https://doi.org/10.1038/s41467-020-16941-y

12. Giampietro M, Funtowicz SO (2020) From elite folk science to the policy legend of the circular economy. Environ Sci Pol 109:64-72. https://doi.org/10.1016/j.envsci.2020.04.012

13. Murray A, Skene K, Haynes K (2017) The circular economy: an interdisciplinary exploration of the concept and application in a global context. J Bus Ethics 140:369-380. https://doi.org/10.1007/s10551-015-2693-2

14. Korhonen J, Nuur C, Feldmann A, Birkie SE (2018) Circular economy as an essentially contested concept. J Clean Prod 175:544-552. https://doi.org/10.1016/j.jclepro.2017.12.111

15. Genovese A, Pansera M (2020) The circular economy at a crossroads: technocratic eco-modernism or convivial technology for social revolution? Capital Nat Social:1-19

16. Blum NU, Haupt M, Bening CR (2020) Why "circular " doesn't always mean "sustainable." Resour Conserv Recycl 162, 105042. https://doi.org/10.1016/j.resconrec.2020.105042

17. Lieder M, Rashid A (2016) Towards circular economy implementation: a comprehensive review in context of manufacturing industry. J Clean Prod 115:36-51. https://doi.org/10.1016/j.jclepro.2015.12.042

18. Pieroni M. de P, McAloone T, Pigosso D (2019) Business model innovation for circular economy: integrating literature and practice into a conceptual process model. Proc. Int. Conf. Eng. Des. ICED 2019-Augus, 2517-2526. https://doi.org/10.1017/dsi.2019.258

19. Ghisellini, P., Ulgiati, S., 2019. Circular economy transition in Italy. Achievements, perspectives and constraints. J Clean Prod 243. https://doi.org/10.1016/j.jclepro.2019.118360

20. COM, 2015. Closing the loop - an EU action plan for the circular economy. Communication from the Commission to the European Parliament, the Council, the European Economic and Social Committee and the Committee of the Regions. Brussels, 2.12.2015. COM(2015) 614 final.

21. EUROSTAT (2020) Domestic material consumption per capita [WWW Document]. URL https://ec.europa. eu/eurostat/databrowser/view/t2020_rl110/default/table?lang=en (accessed 1.19.21).

22. Alcott B (2005) Jevons' paradox. Ecol Econ 54(1):9-21 
23. Zink T, Geyer R (2017) Circular economy rebound. J Ind Ecol 21(3):593-602

24. Odum HT, Odum EP (2000) The energetic basis for valuation of ecosystem services. Ecosystems 3:21-23

25. Brown MT, Ulgiati S (2015) Chapter 2 - the tertiary economy: a threat to the global economy. In: Reddy BS, Ulgiati S (eds) Energy Security and Development - The Global Context and Indian Perspectives, Springer India, vol 2015, pp 1689-1699. https://doi.org/10.1007/978-81-322-2065-7_2

26. Brown MT, Ulgiati S (2011) Understanding the global economic crisis: a biophysical perspective. Ecol Model 223:4-13. https://doi.org/10.1016/j.ecolmodel.2011.05.019

27. Marques L (2020) Capitalism and environmental collapse, 1st ed. Springer International Publishing. https:// doi.org/10.1007/978-3-030-47527-7

28. Santagata R, Zucaro A, Viglia S, Ripa M, Tian X, Ulgiati S (2020) Assessing the sustainability of urban eco-systems through emergy-based circular economy indicators. Ecol Indic 109:105859. https://doi.org/10. 1016/j.ecolind.2019.105859

29. Kelvin WT (1889) Popular lectures and addresses, vol 1. Macmilland and Co., London

30. Gasparatos A, El-Haram M, Horner M (2008) A critical review of reductionist approaches for assessing the progress towards sustainability. Environ Impact Assess Rev 28(4-5):286-311

31. Gasparatos A, Scolobig A (2012) Choosing the most appropriate sustainability assessment tool. Ecol Econ $80(0): 1-7$

32. Gómez-Baggethun E, de Groot R, Lomas PL, Montes C (2010) The history of ecosystem services in economic theory and practice: from early notions to markets and payment schemes. Ecol Econ 69:12091218. https://doi.org/10.1016/j.ecolecon.2009.11.007

33. Kallis G, Gómez-Baggethun E, Zografos C (2013) To value or not to value? That is not the question. Ecol Econ 94:97-105

34. Finkbeiner M, Inaba A, Tan R, Christiansen K, Klüppel HJ (2006) The new international standards for life cycle assessment: ISO 14040 and ISO 14044. Int J Life Cycle Assess 11(2):80-85

35. Suh S (2005) Developing a sectoral environmental database for input-output analysis: the comprehensive environmental data archive of the US. Econ Syst Res 17(4):449-469

36. Lake A, Acquaye A, Genovese A, Kumar N, Koh SCL (2015) An application of hybrid life cycle assessment as a decision support framework for green supply chains. Int J Prod Res 53(21):6495-6521

37. Lenzo P, Traverso M, Salomone R, Ioppolo G (2017) Social life cycle assessment in the textile sector: an Italian case study. Sustainability 9(11):2092

38. Moratis L, Cochius T (2017) ISO 26000: the business guide to the new standard on social responsibility. Routledge

39. Gilliland MW (1975) Energy analysis and public policy. Science 189(4208):1051-1056

40. Calado EA, Leite M, Silva A (2019) Integrating life cycle assessment (LCA) and life cycle costing (LCC) in the early phases of aircraft structural design: an elevator case study. Int J Life Cycle Assess 24(12):2091-2110

41. Santos R, Costa AA, Silvestre JD, Pyl L (2019) Integration of LCA and LCC analysis within a BIM-based environment. Autom Constr 103:127-149

42. Odum HT (1996) Environmental accounting. Emergy and Environmental Decision Making. John Wiley Sons, INC 370. https://doi.org/10.1017/CBO9781107415324.004

43. Brown MT, Ulgiati S (2004) Energy quality, emergy, and transformity: HT Odum's contributions to quantifying and understanding systems. Ecol Model 178(1-2):201-213

44. Corcelli F, Fiorentino G, Vehmas J, Ulgiati S (2018a) Energy efficiency and environmental assessment of papermaking from chemical pulp-a Finland case study. J Clean Prod 198:96-111

45. Corcelli F, Ripa M, Ulgiati S (2018b) Efficiency and sustainability indicators for papermaking from virgin pulp — an emergy-based case study. Resour Conserv Recycl 131:313-328

46. Santagata R, Zucaro A, Fiorentino G, Lucagnano E, Ulgiati S (2020a) Developing a procedure for the integration of Life Cycle Assessment and Emergy Accounting approaches. The Amalfi paper case study. Ecol Indic 117:106676. https://doi.org/10.1016/j.ecolind.2020.106676

47. Faulkner W, Badurdeen F (2014) Sustainable Value Stream Mapping (Sus-VSM): methodology to visualize and assess manufacturing sustainability performance. J Clean Prod 85:8-18. https://doi.org/10.1016/j. jclepro.2014.05.042

48. Hines P, Rich N (1997) The seven value stream mapping tools. Int J Oper Prod Manag 17(1):46-64

49. Vinodh S, Ruben RB, Asokan P (2016) Life cycle assessment integrated value stream mapping framework to ensure sustainable manufacturing: a case study. Clean Techn Environ Policy 18(1):279-295

50. Salvador R, Barros MV, dos Santos GET, van Mierlo KG, Piekarski CM, de Francisco AC (2021) Towards a green and fast production system: integrating life cycle assessment and value stream mapping for decision making. Environ Impact Assess Rev 87:106519

51. Hedlund C, Stenmark P, Noaksson E, and Lilja J (2020) "More value from fewer resources: how to expand value stream mapping with ideas from circular economy." International Journal of Quality and Service Sciences. 
52. Deutsch M (2010) Life cycle cost disclosure, consumer behavior, and business implications. J Ind Ecol 14: 103-120. https://doi.org/10.1111/j.1530-9290.2009.00201.x

53. Costa D, Quinteiro P, Dias AC (2019) A systematic review of life cycle sustainability assessment: current state, methodological challenges, and implementation issues. Sci Total Environ 686:774-787. https://doi. org/10.1016/j.scitotenv.2019.05.435

54. O'Brien M, Doig A, Clift R (1996) Social and environmental life cycle assessment (SELCA): approach and methodological development. Int J Life Cycle Assess 1:231-237. https://doi.org/10.1007/BF02978703

55. Petti L, Serreli M, Di Cesare S (2018) Systematic literature review in social life cycle assessment. Int J Life Cycle Assess 23:422-431. https://doi.org/10.1007/s11367-016-1135-4

56. Sala S, Farioli F, Zamagni A (2013) Life cycle sustainability assessment in the context of sustainability science progress (part 2). Int J Life Cycle Assess 18:1686-1697. https://oi.org/10.1007/s11367-012-0509-5

57. Zamagni A, Feschet P, De Luca AI, Iofrida N, Buttol P (2015) Social life cycle assessment. Sustain. Assess. Renewables-Based Prod. 229-240. https://doi.org/10.1002/9781118933916.ch15

58. Ulgiati S, Raugei M, Bargigli S (2006) Overcoming the inadequacy of single criterion approaches to Life Cycle Assessment. Ecol Model 190:432-442

59. Ulgiati S, Ascione M, Bargigli S, Cherubini F, Franzese PP, Raugei M, Viglia S, Zucaro A (2011) Material, energy and environmental performance of technological and social systems under a Life Cycle Assessment perspective. Ecol Model 222(1):176-189

60. Kirchherr J, Reike D, Hekkert M (2017) Conceptualizing the circular economy: an analysis of 114 definitions. Resour Conserv Recycl 127:221-232. https://doi.org/10.1016/j.resconrec.2017.09.005

61. Moraga G, Huysveld S, Mathieux F, Blengini GA, Alaerts L, Van Acker K, de Meester S, Dewulf J (2019) Circular economy indicators: what do they measure? Resour Conserv Recycl 146:452-461. https://doi.org/ 10.1016/j.resconrec.2019.03.045

\section{Affiliations}

\section{Mariana Oliveira $^{1} \cdot$ Mécia Miguel $^{2,6} \cdot$ Sven Kevin van Langen ${ }^{1,5} \cdot$ Amos Ncube $^{1} \cdot$ Amalia $^{2}$ Zucaro $^{3} \cdot$ Gabriella Fiorentino $^{3} \cdot$ Renato Passaro $^{4} \cdot$ Remo Santagata $^{1} \cdot$ Nick Coleman $^{6}$. Benjamin H. Lowe ${ }^{2} \cdot$ Sergio Ulgiati ${ }^{7,8}$ - Andrea Genovese ${ }^{2}$}

1 International Ph.D. Programme "Environment, Resources and Sustainable Development", Department of Science and Technology, Parthenope University of Napoli, Centro Direzionale, Isola C4, 80143 Napoli, Italy

2 Management School, University of Sheffield, Sheffield, UK

3 ENEA, Laboratory of Technologies for the Reuse, Recycling, Recovery, and Valorisation of Waste and Materials, Portici Research Centre, Napoli, Italy

4 Department of Engineering, Parthenope University of Napoli, Napoli, Italy

5 Supply Chain Department, Olympia Electronics, Aiginio, Greece

6 Tata Steel Europe, Group Sustainability HSE\&Q, Rotherham, UK

7 Department of Science and Technology, Parthenope University of Napoli, Napoli, Italy

8 School of Environment, Beijing Normal University, Beijing, China 